\title{
Editorial
}

\section{Journal of Wrist Surgery in 2020}

\author{
Toshiyasu Nakamura, MD, PhD ${ }^{1}$ \\ ${ }^{1}$ Department of Orthopaedic Surgery, School of Medicine, \\ International University of Health and Welfare, Tokyo, Japan
}

J Wrist Surg 2020;9:1.

I have recorded positive statistics with respect to the fourth issue of the Journal of Wrist Surgery in the year 2018. The number of submissions registered were 136,122 , and 122 in 2016, 2017, and 2018, respectively. In 2019, we received 115 submissions. The authors are widely distributed across the continents of North and South America, Europe, and AsiaPacific. The total full-text HTML and PDF downloads of the articles in 2018 were more than 33,000, compared with the approximate figures of 10,000 in $2014,13,000$ in 2015, 17,000 in 2016 , and 20,000 in 2017. We also received more than 100 citations in the year 2018. The citation in the last 2 years with regard to citable items is quite significant in terms of obtaining an impact factor. This is the primary reason as to why the Journal of Wrist Surgery requires more high-quality papers.

Since 2019, the journal has begun publishing six issues per year. As the Editor-in-Chief, I have asked all reviewers involved in the process of improvement of the standard of submitted manuscripts to ensure that they are of the highest quality. They have also been asked to ascertain if the quality of content of the manuscripts is acceptable and adequate for publication. I always read the submitted manuscripts before sending them out to the reviewers for review. However, when manuscripts are not written adhering to and in accor- dance with the journal style, with issues such as inconsistent reference style, formatting errors, faulty numbering, lowquality figures, ineffective use of tables, and illegible English rearing their heads frequently, it proves to be extremely difficult to read and evaluate their content. On occasions, the manuscript has to be sent back to the concerned authors in order to be corrected before the reviewing process is initiated. These time-consuming affairs can be avoided with careful writing and editing of the manuscript. I would like to appeal to the authors, especially nonEnglish-speaking people, to avail of the services of an English editing company in order to polish the language used in the manuscript.

In this issue, there is a "special review" titled "Pediatric Scaphoid Nonunions: A Case Series, Literature Review, and Guidelines" by Oestreich et al. Thoroughly engaging papers pertaining to the wrist, such as comparison of union period between arthroscopic bone grafting and simple percutaneous screw fixation, anatomical features of thumb carpometacarpal joint, scaphoid fracture, radiographic and computed tomography analysis of Kienböck's disease, watershed line of distal radius, triangular fibrocartilage complex (TFCC) lesions, wrist and carpal anatomy, systematic review of diagnosis of scaphoid fractures, and interesting case reports, find place in this issue. Please make sure you don't miss it.
Address for correspondence Toshiyasu Nakamura, MD, PhD, Department of Orthopaedic Surgery, School of Medicine, International University of Health and Welfare, 8-10-16 Akasaka, Minato-ku, Tokyo 107-0052,

Japan

(e-mail: toshiyasu@ae.em-net.ne.jp).
Copyright $\odot 2020$ by Thieme Medical Publishers, Inc., 333 Seventh Avenue, New York, NY 10001, USA. Tel: +1(212) 760-0888.
DOI https://doi.org/ 10.1055/s-0040-1701264. ISSN 2163-3916. 